\title{
The concise argument
}

doi:10.1136/jme.2010.040048

Søren Holm, Editor

History and consent

This issue contains two papers related to the historical dimensions of medical ethics. The first and most straightforwardly historical paper is the short paper by Selek in which he reports a formal contract for medical services signed before the court in Gaziantep, Turkey in 1539 (see page 639). In the contract the patient's illness and the surgery to be performed are described, the fee stated and the surgeon absolved from responsibility if the patient dies. This contract is in many ways different from current consent forms, but even if it only contains 8 lines of text it still shows that modern legal ideas about consent have ancient roots, and that these roots can be found in many different legal systems.

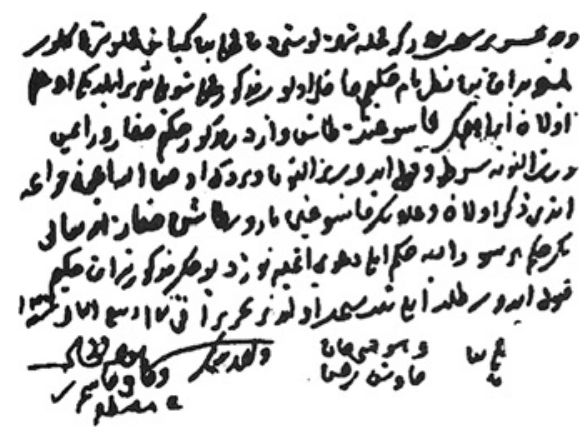

The second paper by Kaufmann and Rühli is concerned with the ethics of research on ancient mummies (see page 608). In these cases there is obviously no consent to research, but there may still be ethical issues that need to be resolved. The authors argue that while we may not be able once and for all to reconcile the many different interests that are at play, we can put in place a reflective process that ensures that all important stakeholders and all important interests are identified and reflected upon. A particularly interesting part of the paper analyses the importance of bodily integrity into four distinct categories of bodily wholeness and discusses the implications for the evaluation of the methods by which we do research on ancient mummies.

\section{Moral conflicts in hospice care}

Hospice care is supposed to help terminal patients to experience a better way of dying than they would experience in a normal hospital. As such we might think that hospices are also places where moral conflicts are rare, but the study by Salloch and Breitsamer shows that this is not necessarily true (see page 588). Based on qualitative interviews with hospice staff and volunteers in Germany they find that moral conflicts occur when the virtue ethics orientation and the commitment to holistic care at the end of life that is characteristic of the hospice movement is confronted by patients who do not accept that they have an incurable disease or when there are disagreements among the patients' families.

\section{Theory and the teaching of medical ethics}

One of the perennial bones of contention in the teaching of medical ethics is the role of moral theory. Should moral theory be taught, and if so to what extent? In the JME we have had a number of papers arguing on both sides of this debate. In the current issue Ben Saunders suggests that the debate has, at least in part not been about the teaching of moral theory as such, but about whether teaching should be theory-led (see page 635). He agrees with the critics of theory that teaching should not be theory-led in any uncritical way, but points out that moral theory can be taught nevertheless. There is nothing that prevents us from starting with practical cases and then drawing on theory, if and when it becomes relevant to students. Such an approach will, he suggests lead to a situation where '..., theories are taught but students do not take them to be the $\alpha$ and $\omega$ of moral thinking.'

I think I agree with him.

\section{Teaching professionalism and scientific integrity}

The authors of another paper in this issue are also likely to agree with Saunders. Jones et al report on the design and implementation of a problem-based learning (PBL) curriculum for professionalism and scientific integrity training for biomedical graduate students (see page 614). The authors explain the rationale behind choosing a PBL approach and shows that the opportunities for active learning that this approach opens were welcomed by both staff and students. Each part of a PBL curriculum is fundamentally case based, but this does not entail that theory plays no role. In the current context cases where designed to elicit reflection on the '... underlying philosophies for the ethical practice of science...'. 